\title{
Application of SMES-FCL in Electric Aircraft for Stability Improvement
}

\author{
Hamoud Alafnan, Mariam Elshiekh, Xiaoze Pei, Shadan Altouq, Seyed Mahdi Fazeli, Qixing Sun, \\ Min Zhang, Weijia Yuan
}

\begin{abstract}
The increase in aircraft passengers and airfreight traffic has given rise to concerns about greenhouse gas emissions for traditional aircraft and the resulting damage to the environment. This has led several companies and organizations, including NASA, to set goals to enhance aircraft efficiency as well as reduce fuel burn, pollution, and noise for commercial aircraft. The most notable electric aircraft (EA) concept is the N3-X, which was developed by NASA to achieve environmental goals while maintaining the annual growth of the aviation industry. However, one of the main challenges that EA facing is their overall weight. This paper proposes and explores an improved power system architecture for use in EA based on the N3-X concept. The number of superconducting magnetic energy storage (SMES) and fault current limiter (FCL) devices required can be reduced by utilizing multifunctional superconducting devices that combine the functionalities of both a SMES and a FCL, thus reducing the weight and cost of the EA by eliminating a complete device. The proposed control technique offers greater flexibility in determining the appropriate size of coils to function as a FCL, based on the fault type. The proposed EA power system architecture including the SMES-FCL devices is modelled in Simulink/Matlab to test the system performance under different failure scenarios.
\end{abstract}

Index Terms — Electric aircraft (EA), fault current limiter (FCL), superconducting magnetic energy storage (SMES), turboelectric distributed propulsion system (TeDP).

\section{INTRODUCTION}

$\mathbf{T}$ RANSPORTATION and electricity generation are the largest sources of carbon dioxide $\left(\mathrm{CO}_{2}\right)$ emissions in the US, at $34 \%$ per each, $68 \%$ in total [1]. The annual increase in aircraft passengers is estimated to be $6.5 \%$, while the annual freight traffic growth rate is $4.4 \%$ [2], meaning that with current aviation transportation technology, $\mathrm{CO}_{2}$ emissions will continue to increase dramatically. Because concerns about global warming and pollution are increasing, many companies and organizations have set goals to limit atmospheric pollution and

This work was funded as part of the UK EPSRC, Developing Superconducting Fault Current Limiters (SFCLs) for Distributed Electric Propulsion Aircraft: EP/S000720/1.

H. Alafnan, M. Elshiekh, X. Pei, Sh. Altouq, S. Fazeli and Q. Sun are with the Department of Electronic and Electrical Engineering, University of Bath, Bath BA2 7AY, UK (e-mail: hfa25@bath.ac.uk). M. Elshiekh is currently visiting the Department of Electronic and Electrical Engineering, University of Strathclyde

M. Zhang, W. Yuan are with the Department of Electronic and Electrical Engineering, University of Strathclyde, Glasgow, G1 1XW, UK.

(e-mail: Weijia.yuan@strath.ac.uk)

H. Alafnan is with the Department of Electrical Engineering, University of Hail, Hail, 55476, KSA.

M. Elshiekh is with the Department of Electrical Power and Machines Engineering, Faculty of Engineering, Tanta University, Tanta 3152, Egypt.
TABLE I

NASA AND ACARE ENVIRONMENTAL GOALS

\begin{tabular}{ccccc}
\hline \hline Category & ACARE & ACARE & NASA N+2 & NASA N+3 \\
& 2020 & 2050 & $\sim 2020$ & $\sim 2030$ \\
\hline $\mathrm{CO}_{2}$ reduction & $50 \%$ & $75 \%$ & - & - \\
$\mathrm{NO}_{x}$ reduction & $80 \%$ & $90 \%$ & $75 \%$ & $80 \%$ \\
Ex. noise & $50 \%$ & $65 \%$ & $-42 \mathrm{~dB}$ & $-71 \mathrm{~dB}$ \\
Fuel burn & $50 \%$ & - & $50 \%$ & $60 \%$ \\
\hline
\end{tabular}

greenhouse gas emissions, such as the National Aeronautics and Space Administration (NASA) and the Advisory Council for Aviation Research and Innovation in Europe (ACARE). The NASA and ACARE environmental goals relative to year 2000 are shown in Table I [3], [4]. As can been seen in Table I, the targeted improvements for both NASA N+3 and ACARE 2050 are extremely high, whereby reductions of $\mathrm{CO}_{2}$ by $75 \%, \mathrm{NO}_{x}$ by $90 \%$, and external noise by $65 \%$ are infeasible in traditional aircraft design (gas turbine or piston engine) due of the relatively low efficiency $\sim 40 \%$ [5]. To achieve such goals, the aircraft, including the propulsion system, must work with superior efficiency.

The most notable EA concept is the N3-X, which has a range of 22.5 MVA for passenger aircraft and was proposed by NASA's Research and Technology for Aerospace Propulsion Systems (RTAPS) [6]. The N3-X combines the advantages of a turboelectric distributed propulsion system (TeDP), boundary layer ingestion (BLI), and superconducting technology to achieve the highest possible efficiency with the minimal weight. The N3-X power system architecture, known as the Inner Bus Tie Concept (IBTC), consists of four generators that supply 16 propulsors throughout a DC microgrid to give the required thrust.

However, there is a possibility that short fault currents may occur when this system is employed in larger passenger aircraft due to significant in-flight vibration or adverse weather conditions. Such occurrences may consequently cause serious permanent faults that can, if not properly addressed, lead to onboard fire, power disruption, system damage, or catastrophic failure [7],[8].

In the N3-X concept, NASA proposed the use of superconducting fault current limiter (SFCL) and superconducting magnetic energy storage (SMES) devices. A SFCL provides very effective current limitation within a few milliseconds [9]-[11]. which can offer a solution to the issue of short fault currents. SMES devices have a higher power density, faster time response, and unlimited charge and discharge lifecycles compared to other energy storage technologies [12],[13]. Such advantages are important for EA performance, where system reliability is a crucial point. 


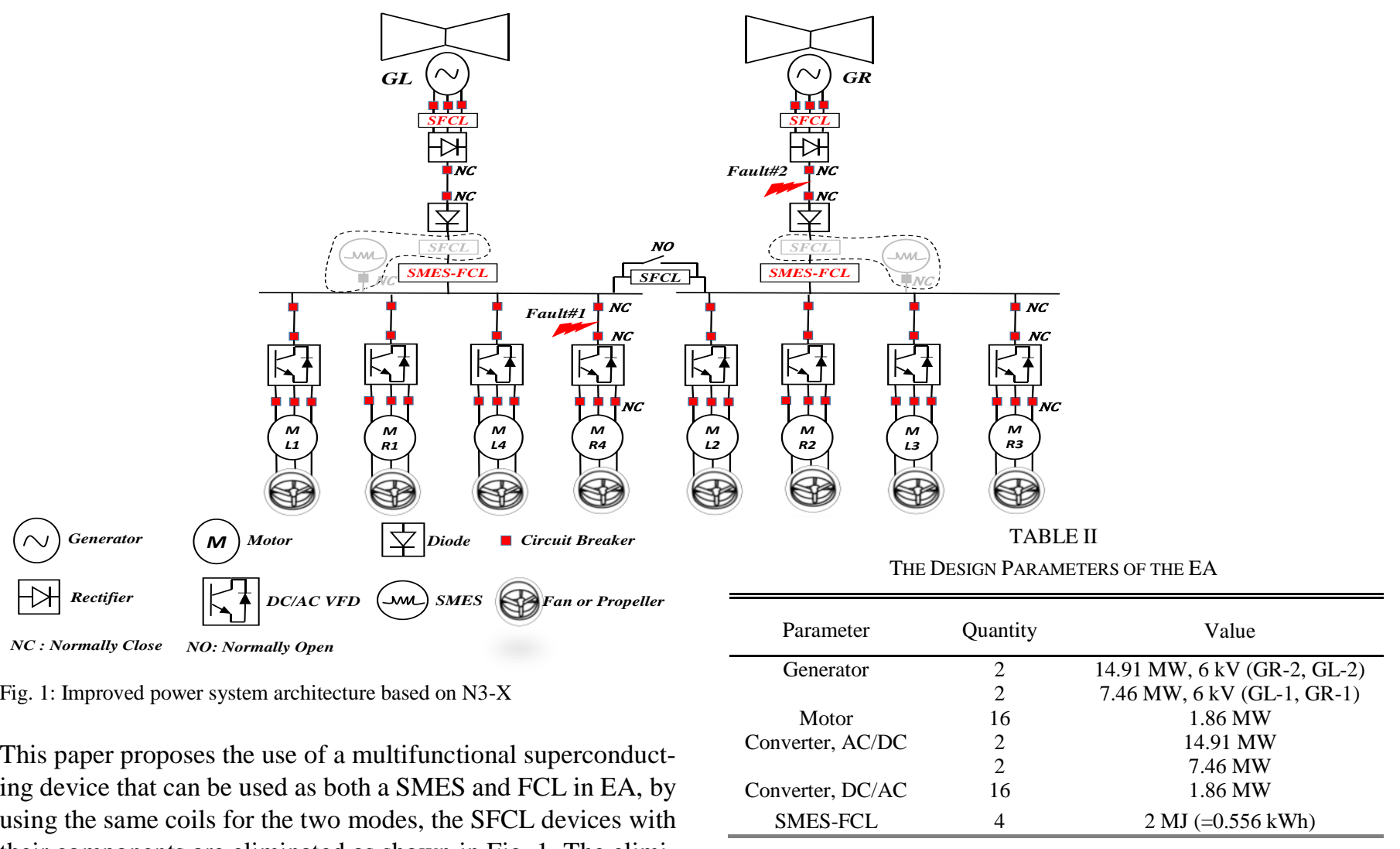

their components are eliminated as shown in Fig. 1. The elimination of a complete device can reduce the overall weight and cost of the EA. The proposed control algorithm allows the super conducting coils to work as a SMES or part of the coils as a FCL, based on the fault type. Multipurpose superconducting coils have been proposed in several applications, including in wind farms for AC and DC networks [14],[15]. For a DC network, previous work has suggested the use of the whole coil as a SMES or a FCL. However, the proposed control technique offers greater flexibility to determine the appropriate size of the coils to work as an FCL based on the fault current. The proposed power system architecture, including the control algorithm, is modelled and tested under different fault scenarios using the Simulink/Matlab environment.

\section{SYSTEM DESCRIPTION}

The N3-X TeDP power system architecture, the Inner Bus Tie Concept (IBTC), proposed by NASA [16], was chosen as the platform for testing the performance of the SMES-FCL devices under various fault scenarios. The system components are shown in Table II.

The capacities of the generators, motors, and converters are based on the data of the aircraft proposed by NASA [16]. The SMES-FCL device capacity is calculated to supply a set of four motors for $320 \mathrm{~ms}$ at a cruise rated power of $1.5625 \mathrm{MW}$ per motor. The propulsion system is required to produce $22.5 \mathrm{MW}$ for maximum thrust during take-off [17].

Because each motor can produce $1.86 \mathrm{MW}$ thrust, at least 12 motors are required to work at the same time to ensure a stable operation. The voltage DC-link is rated at $6 \mathrm{kVDC}$, as recommend by NASA [18]. The multifunctional superconducting devices can replace the SMES and SFCL devices, which helps to reduce both the weight and cost of the EA while maintaining the same performance. In this paper, half of the power system architecture of the N3-X has been modelled, with eight motors (1.86 MW) and two generators (14.91 MW) as shown in Fig. 1, instated of the full sixteen motors and four generators [16].

\section{A. SMES-FCL Device.}

Due to its fast response, a SMES works well to maintain the voltage at the DC-link and ensures a stable operation for the propulsion system, which is a crucial for the EA design. SMES devices have been proposed and used in several applications, including a hybrid vehicle, electric ships, and microgrids [19][21]. The stored energy of a SMES is calculated as follows:

$$
E_{\text {smes }}=\frac{1}{2} L I_{S M E S}^{2}
$$

where $L$ is the inductance in Henry, $I_{S M E S}$ is the current stored in the SMES, and $E_{\text {smes }}$ is the stored energy in SMES in Joule.

Resistive type superconducting fault current limiters are considered self-recovery devices. When the current passing through the SFCL coils exceeds their critical current, the SFCL resistance starts to increase dramatically, according to the following equation [22]:

$$
\rho_{H T S}=\frac{E_{c}}{J_{c}(T)}\left(\frac{J}{J_{c}(T)}\right)^{N-1} T<T_{c}, \quad J>J_{c}
$$


where $\mathrm{Ec}=1 \mu \mathrm{V} / \mathrm{cm}$ is the critical electrical field. The $\mathrm{N}$ value is usually between 21 and 30 for Yttrium Barium Copper Oxide (YBCO) tapes. When the applied current is greater than the critical current, a joule heating effect occurs due to the exponential rise in $\rho_{H T S}$, leading to a rise in the temperature of the superconducting material.

$$
J_{c}(T)=J_{c o}\left(\frac{\left(T_{c}-T(t)\right)^{\alpha}}{\left(T_{c}-\left(T_{o}\right)^{\alpha}\right.}\right) \quad T<T_{c}
$$

where $\alpha$ is 1.5 , which is applicable to YBCO superconducting materials, $J_{c o}$ is the critical current density at the initial temperature $T_{o}$. As the current density $J_{c}(T)$ is less than the critical current density $J_{c o}$, the coils' resistance will be neglected. However, when the current passing through the coils exceeds the critical current, the coils resistance starts to increase and limits the high fault currents. The concept of the resistive type SFCL is used to limit the fault currents in the EA system using the SMES coil.

The SMES-FCL device provides the two types of operation by using the same coils. For the SMES operation mode, the whole coil can be used to achieve the highest energy capacity. However, a few pancakes will be enough to achieve the desired limitation without affecting the system stability or the coil itself. In this study, a resistance value of $2 \Omega$ is used as the fault current limiting resistance.

The SMES coils comprise 67 pancakes with an inductance of $1.005 \mathrm{H}$ and a current rating of $2 \mathrm{kA}$. The SMES capacity is calculated by (1) to be $2 \mathrm{MJ}$ [23],[24]. With regards to YBCO material containing copper stabilizer, it is possible to achieve a resistance value of $2 \Omega$ through the use of two pancakes, whereby each one consists of $50 \mathrm{~m}$ of superconducting tape. If it were wound into a single pancake structure with an inner diameter of $10 \mathrm{~cm}$ and width of $4 \mathrm{~mm}$, this particular design would correspond to an inductance of approximately $15 \mathrm{mH}$ [14],[25].

\section{B. Electric Propulsion Motor.}

In this system, surface permanent magnet synchronous motors (SPMSM) are used as the electric propulsion due to the high power density and high efficiency [26]. The power capacity, number of pair poles, and nominal speed of each propulsion motor is $1.86 \mathrm{MW}, 4$, and $4000 \mathrm{rpm}$, respectively.

The principle of controlling the motors is based on the Field Oriented Control (FOC) strategy [27], as shown in Fig. 2. To implement the FOC strategy, the control unit translates the stator variables (currents) into a d-q frame coordination based on the rotor position as well as to compare the values with the reference values $\left(\omega_{\text {ref }}, i_{\text {qref }}\right.$ and $\left.i_{\text {dref }}\right)$, and updates the PI controllers. The inverter gate signals are updated after the back transformation of the new voltage references into the stator frame coordination and compared with the modulating signals. In order to achieve the Maximum Torque Per Ampere (MTPA) strategy, $i_{\text {dref }}$ is set to zero for the whole time [28] and the gains of all PI blocks have been fine-tuned by control theory analysis together with trial and error adjustments. In Fig. 2, S1-S6 are insulatedgate bipolar transistors (IGBTs) with integrated, anti-parallel diodes.



Fig. 2: Field Oriented Control (FOC) for an electric propulsion motor.

\section{SMES-FCL CONTROL METHOD}

The multifunctional superconducting coils are designed to work in two different operation modes based on the fault position. If the fault occurs on the propulsion side, as is the case in Fault \#1, part of the superconducting coils work as a FCL to limit the fault current and the rest of the coils are isolated to protect them from the overcurrent. However, if the fault occurs on the generation side, as is the case in Fault \#2 in Fig.1, the superconducting coil works as a SMES to maintain the speed of the propulsion system and the voltage at the DC-link.

The SMES-FCL device is programmed based on the current and the voltage measurements on the DC bus. If the fault occurs at the generation side as in Fault \#2, both the current and voltage on the DC bus drop; as a result, the SMES-FCL works as a SMES in discharge mode, as shown in Fig. 3 (a). During the normal operation, the switches, S1, S4 and S5 are closed, S2, S3 and S6 are open. When the SMES-FCL works in SMES operation mode, the switches I1 and I2 control the discharge rate of the SMES based on the control algorithms which allow the two switches to discharge the appropriate amount of current to maintain the DC-link voltage at the acceptable level and the motor speed at the reference speed.

If the fault occurs on the propulsion side as in Fault \#1, the current increases dramatically and the DC bus voltage drops. In this case, the SMES-FCL works as a FCL to limit the fault current and isolate the rest of the coils for protection, as shown in Fig. 3 (b), whereby two pancakes are used as a FCL, as shown by the red arrows, and the rest of the coils are isolated for protection, as shown by the green arrows. For the FCL mode, the switching sequence is: I1 is off and I2 is on to put the coils in the standby mode. Then, S2, S3, and S6 are closed to isolate the SMES coils for protection. Finally, S1, S4 and S5 are opened to force the current to go through the two pancakes which is the FCL part to limit the fault current. In Fig. 3, S1-S6 are unidirectional, reverse blocking IGBTs. More details pertaining to controlling I1 and I2 in the SMES mode can be found in [20]. Fig. 3 (c) shows the SMES charging mode of the SMES-FCL, and Fig. 3 (d) shows the SMES standby mode. 


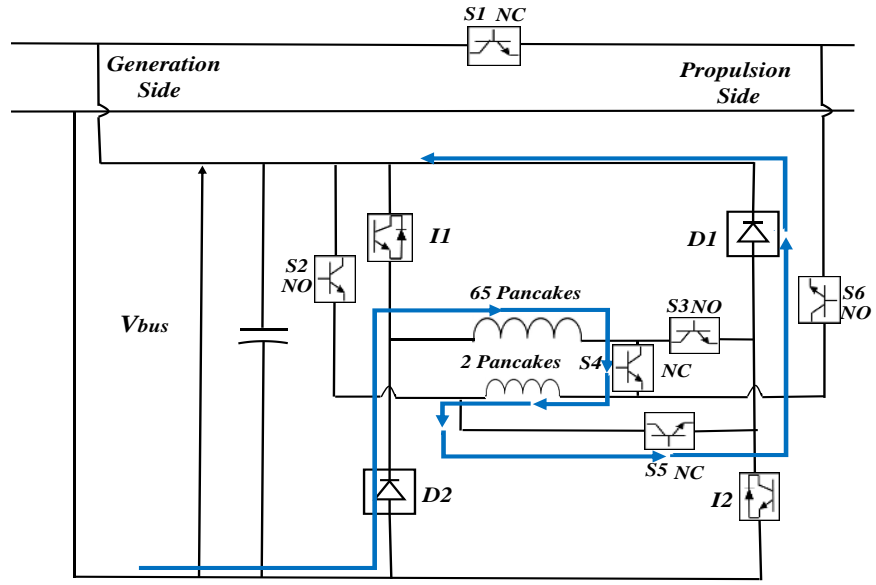

(a)

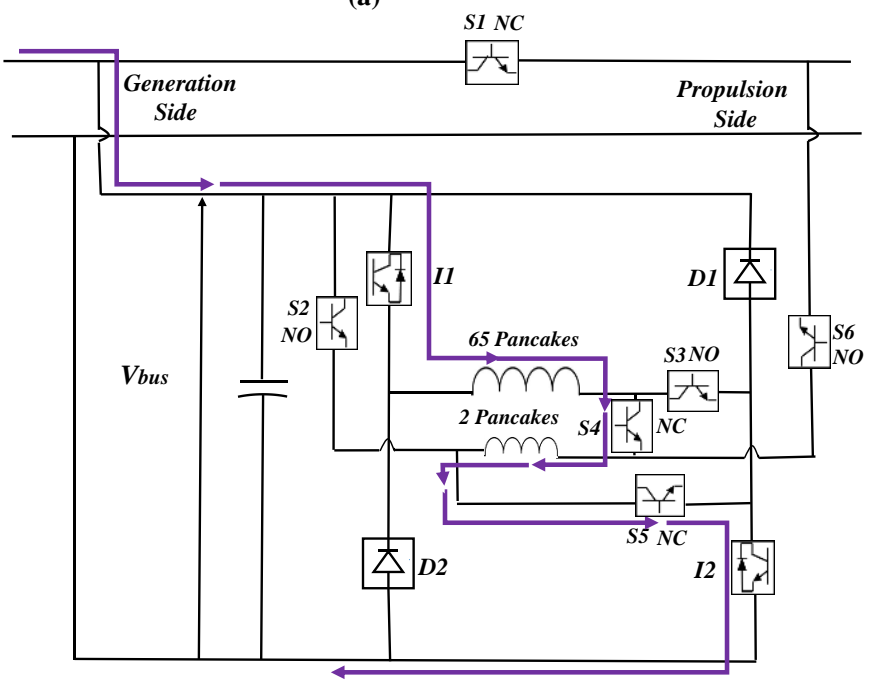

(c)

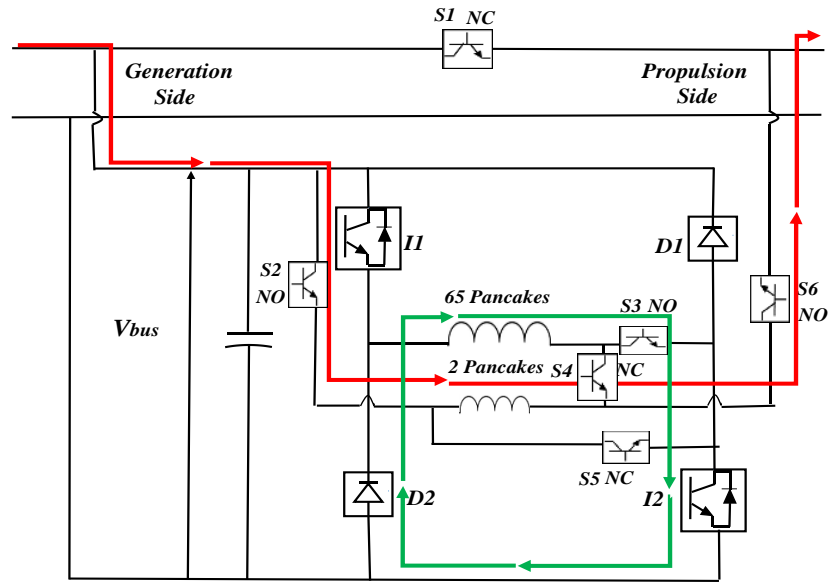

(b)

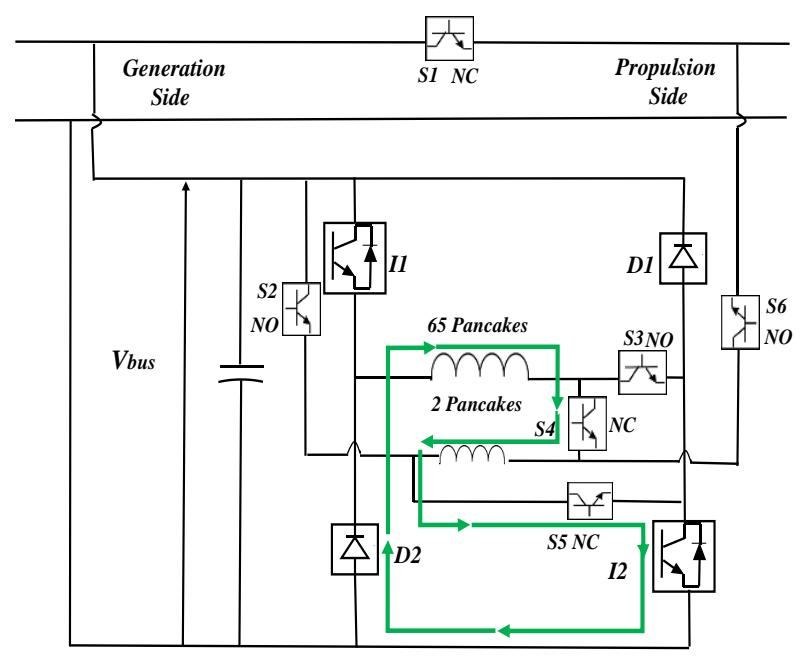

(d)

Fig. 3: SMES-FCL control topology, (a) SMES discharge mode, (b) FCL mode, (c) SMES charge mode, and (d) SMES standby mode.

\section{Simulation Results \& Discussion}

The power system architecture of the EA shown in Fig. 1 is modelled in the SimPower ${ }^{\mathrm{TM}}$ Simcape ${ }^{\mathrm{TM}}$ systems environments to test the performance of the SMES-FCL devices under different fault scenarios. Based on the control topology, Fault \#1 made the SMES-FCL device work in the FCL mode, while Fault \#2 made the SMES-FCL device work in the SMES mode. To show different types of DC faults in the DC microgrid of the EA, a pole-to-pole and pole-to-ground faults are applied at the location of Fault \#1, while Fault \#2 is a pole-to-ground fault [29]. The aircraft grounding method employed in this paper is based on a current return network (CRN) formed by the traditional metallic aircraft structure, with additional cables where required, thus ensuring a low electrical impedance (max. 0.1 to 0.2 ohms) [7], [30].

\section{1) FCL mode (Fault \#1):}

When the system is subjected to a pole-to-pole fault current at the propulsion side, the SMES-FCL works in the FCL mode to limit the high current, as shown in Fig. 3(b). The fault lasts for $100 \mathrm{~ms}$, from $5.0 \mathrm{~s}$ to $5.1 \mathrm{~s}$. The current in the main feeder is shown in Fig. 4(a) in three cases: With and without the SMES-FCL device and with the separate SMES and FCL devices. Without the SMES-FCL, the current increases dramatically, whereas with the combined SMES-FCL, the FCL is able to limit the current to almost twice the rated current in few milliseconds. Fig. 4(b) shows the voltage at the generation side; without the SMES-FCL, the voltage drops to almost 0.23 pu of the nominal voltage, whereas with the SMES-FCL, the voltage is maintained above $0.86 \mathrm{pu}$. The generator speed is maintained above 0.98 pu of the nominal speed with the SMES-FCL; however, the speed drops to almost $0.94 \mathrm{pu}$ of the nominal speed without the SMES-FCL device, as shown in Fig. 4 (c). It is noticeable that the separate FCL device works slightly faster than the combined SMES-FCL, but that is due to the latter using. switches. For all results in this section, the circuit breakers do not trip, showcasing the performance of the SMES-FCL device.

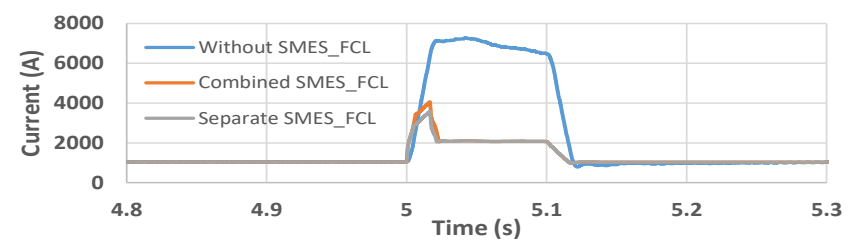

(a) 


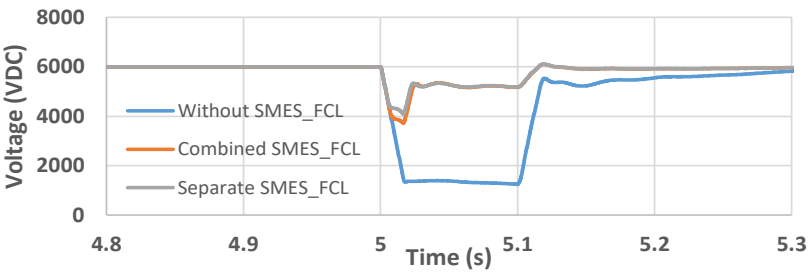

(b)

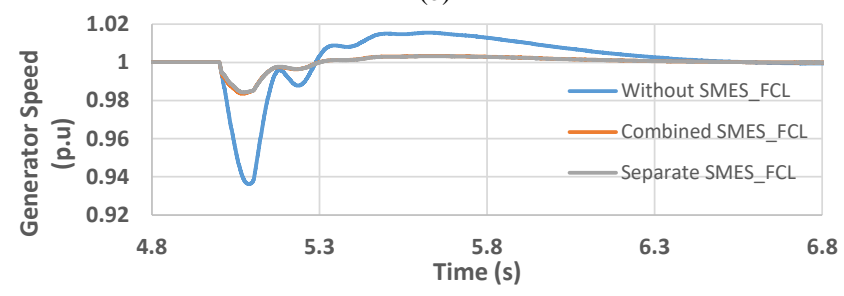

(c)

Fig. 4: Pole-to-pole fault on the propulsion side Fault \#1 (a) Current without SMES-FCL, with combined SMES-FCL, and with separate SMES-FCL, (b) Voltage without SMES-FCL, with combined SMES-FCL, and with separate SMES-FCL, (c) Generator speed without SMES-FCL, with combined SMESFCL, and with separate SMES-FCL

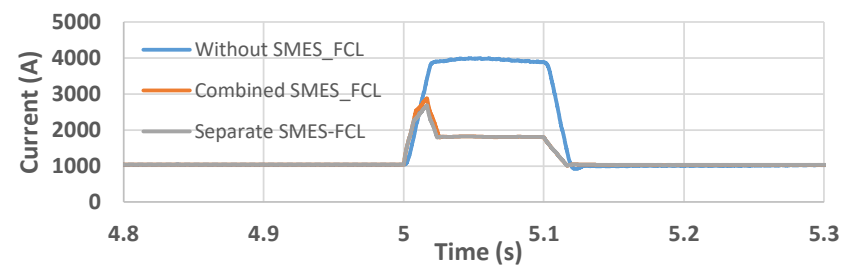

(a)

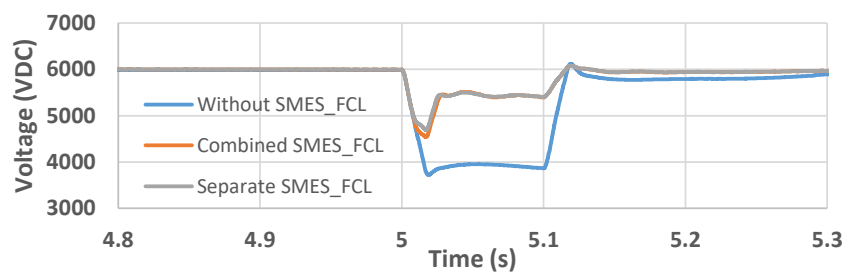

(b)

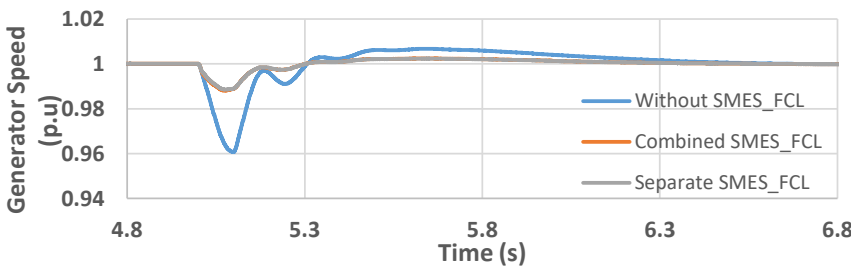

(c)

Fig. 5: Pole-to-ground fault on the propulsion side Fault \#1 (a) Current without SMES-FCL, with combined SMES-FCL, and with separate SMES-FCL, (b) Voltage without SMES-FCL, with combined SMES-FCL, and with separate SMES-FCL, (c) Generator speed without SMES-FCL, with combined SMES-FCL, and with separate SMES-FCL.

Fig. 5 shows the effect of a pole-to-ground fault at the location of Fault \#1 on the current, the bus voltage, and the generator speed in the same three cases explored in Fig. 4. It is clear that these effects are larger in magnitude during a pole-to-pole fault than in the pole-to-ground fault due to the higher potential voltage in the pole-to-pole fault.

\section{2) SMES mode (Fault \#2):}

If the fault current occurs on the generation side, the SMESFCL works in the SMES mode to maintain the voltage at the required level and maintain the propulsion system speed at the desired speed. When both the voltage and current drop at the DC-link, the SMES-FCL works as a SMES by discharging current to supply the propulsion system. The system was subjected to a pole-to-ground fault at the position of Fault \#2, as shown in Fig. 1. The fault lasts for $100 \mathrm{~ms}$ from $5.0 \mathrm{~s}$ to $5.1 \mathrm{~s}$. The system works in the discharged mode, as shown in Fig. 3 (a). The SMES is able to maintain the voltage at the required level and the motors' speed at the reference speed. Fig. 6 (a) shows the speed of motor MR3 in the three different cases. Fig. 6 (b) shows the voltage at the DC-link in the three different cases. When the voltage dropped due to the fault current, the SMES discharged within few milliseconds as shown in in Fig. 6 (c). Here, the combined SMES-FCL and the separate devices act in the same way with no additional delay since the additional switches (S1-S6) are not used in this scenario.

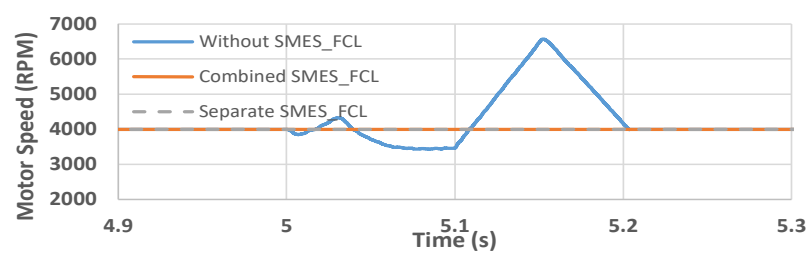

(a)

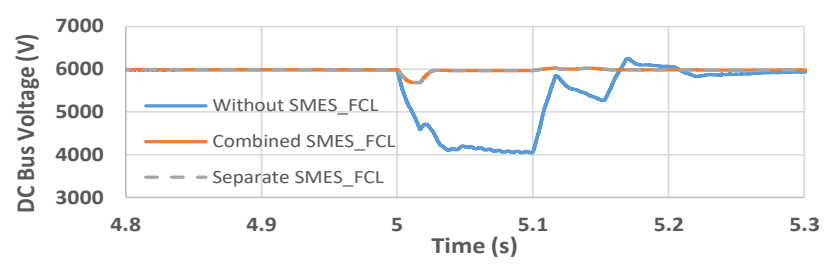

(b)

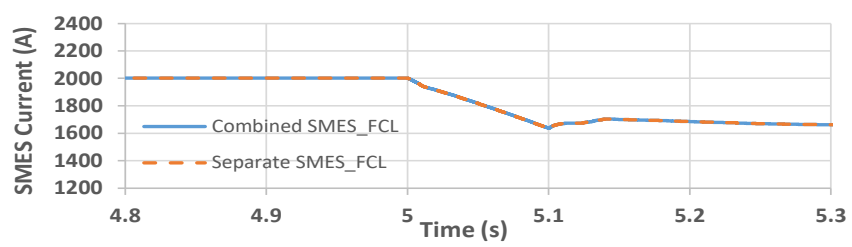

(c)

Fig. 6: Pole-to-ground fault on the generation side Fault \#2 (a) Propulsion motor speed of MR3 without SMES-FCL, with combined SMES-FCL, with separate SMES-FCL, (b) Voltage without SMES-FCL, with combined SMES-FCL, and with separate SMES-FCL, (c) SMES current with combined SMES-FCL and with separate SMES-FCL.

\section{CONCLUSIONS}

This paper proposed the use of multifunction superconducting coils in the EA using a novel control technique. The proposed SMES-FCL can reduce the weight as well as the cost of EA by using the same coils in different operation modes. However, one of the potential negative side-effects of the combined SMES-FCL is the complexity of the design. Also, the SMES and FCL can work simultaneously when they are separate, whereas it is not possible in the combined device. And finally, the separate SMES and FCL can respond to faults slightly faster than the combined SMES-FCL due to the use of switches in the combined device. 
The SMES-FCL device has been tested in three different fault scenarios. In the FCL mode, the SMES-FCL device was able to reduce the fault current from 7 times to almost twice the rated current within a few milliseconds, maintaining the voltage at above $0.86 \mathrm{pu}$ of the nominal voltage, instead of 0.23 pu without the SMES-FCL device, and maintaining the generator speed at above $0.98 \mathrm{pu}$, instead of $0.94 \mathrm{pu}$ without the SMES-FCL device. In the SMES mode, the SMES-FCL device was able to maintain the propulsion system speed at the required speed and the voltage at the DC-link at the reference voltage.

\section{REFERENCES}

[1] United States Environmental Protection Agency, "Greenhouse Gas Emissions." [Online]. Available: https://www.epa.gov/ghgemissions/overview-greenhouse-gases.

[2] ECONOMIC DEVELOPMENT, "ICAO." [Online]. Available: https://www.icao.int/sustainability/pages/eap_fp_forecastmed.aspx.

[3] K. L. Suder, "Overview of the NASA Environmentally Responsible Aviation Project's Propulsion Technology Portfolio," 48th AIAA/ASME/SAE/ASEE Jt. Propuls. Conf. Exhib., no. August, pp. 123, 2012.

[4] ACARE, "Strategic Research \& Innovation Agenda," 2017. [Online]. Available:

https://www.acare4europe.org/sites/acare4europe.org/files/attachme $\mathrm{nt} /$ acare-strategic-research-innovation-volume-1-v2.7-interactivefin_0.pdf.

[5] A. H. Epstein, "Aeropropulsion for Commercial Aviation in the Twenty-First Century and Research Directions Needed," AIAA J., vol. 52, no. 5, pp. 901-911, 2014.

[6] M. J. Armstrong, C. A. H. Ross, and M. J. Blackwelder, "Trade Studies for NASA N3-X Turboelectric Distributed Propulsion System Electrical Power System Architecture," 2016.

[7] C. E. Jones et al., "Electrical and thermal effects of fault currents in aircraft electrical power systems with composite aero-structures," IEEE Trans. Transp. Electrif., vol. 4, no. 3, pp. 1-1, 2018.

[8] A. Yaramasu, Y. Cao, G. Liu, and B. Wu, "Aircraft electric system intermittent arc fault detection and location," IEEE Trans. Aerosp. Electron. Syst., vol. 51, no. 1, pp. 40-51, 2015.

[9] D. E. A. Mansour and D. M. Yehia, "Analysis of 3-phase superconducting fault current limiters in power systems with inhomogeneous quenching," IEEE Trans. Appl. Supercond., vol. 23, no. 3, pp. 1-5, 2013.

[10] N. Y. Kwon et al., "The effects of a stabilizer thickness of the YBCO coated conductor (CC) on the quench/recovery characteristics," IEEE Trans. Appl. Supercond., vol. 20, no. 3, pp. 1246-1249, 2010.

[11] D. M. Yehia and D. E. A. Mansour, "Modeling and Analysis of Superconducting Fault Current Limiter for System Integration of Battery Banks," IEEE Trans. Appl. Supercond., vol. 28, no. 4, 2018.

[12] T. M. I. Mahlia, T. J. Saktisahdan, A. Jannifar, M. H. Hasan, and H. S. C. Matseelar, "A review of available methods and development on energy storage; technology update," Renew. Sustain. Energy Rev., vol. 33, pp. 532-545, 2014.

[13] J. Li, R. Xiong, Q. Yang, F. Liang, M. Zhang, and W. Yuan, "Design/test of a hybrid energy storage system for primary frequency control using a dynamic droop method in an isolated microgrid power system," Appl. Energy, vol. 201, pp. 257-269, 2017.

[14] M. E. Elshiekh, D. E. A. Mansour, M. Zhang, W. Yuan, H. Wang, and M. Xie, "New technique for using SMES to limit fault currents in wind farm power systems," IEEE Trans. Appl. Supercond., vol. 28, no. $4,2018$.

[15] I. Ngamroo and T. Karaipoom, "Improving Low-Voltage RideThrough Performance and Alleviating Power Fluctuation of DFIG Wind Turbine in DC Microgrid by Optimal SMES with Fault Current Limiting Function," IEEE Trans. Appl. Supercond., vol. 24, no. 5, 2014.
Turboelectric Distributed Propulsion Electric Grid, no. July. 2015.

M. J. Armstrong, C. A. H. Ross, M. J. Blackwelder, and K. Rajashekara, "Propulsion System Component Considerations for NASA N3-X Turboelectric Distributed Propulsion System," SAE Int. J. Aerosp., vol. 5, no. 2, pp. 2012-01-2165, 2012.

[18] K. H. Paul Gemin, Tom Kupiszewski, and Arthur Radun, Yan Pan, Rixin Lai, Di Zhang, Ruxi Wang, Xinhui Wu, Yan Jiang, Steve Galioto and and A. C. William Premerlani, Jim Bray, "Architecture, Voltage and Components for a Turboelectric Distributed Propulsion Electric Grid (AVC-TeDP)," no. July, pp. 1-107, 2015.

[19] Li J, Yang Q, Robinson F, Liang F, Zhang M, Yuan W. Design and test of a new droop control algorithm for a SMES/battery hybrid energy storage system. Energy. 2017;118:1110-22

[20] H. Alafnan et al., "Stability Improvement of DC Power Systems in an All-Electric Ship Using Hybrid SMES/Battery," IEEE Trans. Appl. Supercond., vol. 28, no. 3, 2018.

[21] A. Cansiz, C. Faydaci, M. T. Qureshi, O. Usta, and D. T. Mcguiness, "Integration of a SMES - Battery-Based Hybrid Energy Storage System into Microgrids," J. Supercond. Nov. Magn., pp. 1-9, 2017.

[22] F. Liang, W. Yuan, C. A. Baldan, M. Zhang, and J. S. Lamas, "Modeling and Experiment of the Current Limiting Performance of a Resistive Superconducting Fault Current Limiter in the Experimental System," J. Supercond. Nov. Magn., vol. 28, no. 9, pp. 2669-2681, 2015.

[23] D. Rogers, L. Alamos, and J. F. Hauer, "Ieee transactions," vol. M, no. $2,1985$.

[24] P. Tixador, "Superconducting Magnetic Energy Storage : Status and Perspective," IEEE/CSC ESAS Eur. Supercond. News Forum, no. 3, pp. 1-14, 2008.

[25] S. Kar and V. V. Rao, "Comparative study on the fastest effective fault limitation for stabilized and stabilizer-free high Tc superconductors," Phys. C Supercond. its Appl., vol. 541, pp. 50-54, 2017.

[26] S. Li and Z. Liu, "Adaptive speed control for permanent-magnet synchronous motor system with variations of load inertia," IEEE Trans. Ind. Electron., vol. 56, no. 8, pp. 3050-3059, 2009.

[27] A. D. Alexandrou, N. K. Adamopoulos, A. G. Kladas, and S. Member, "Development of a Constant Switching Frequency Deadbeat Predictive Control Technique for Field Oriented Synchronous Permanent Magnet Motor Drive," vol. 0046, no. c, pp. 5167-5175, 2016.

[28] S. Motor, U. I. Feedback, and F. Engineering, "Adaptive Sliding Mode Speed Control of surface Permanent Magnet," pp. 1375-1380.

[29] L. ZHANG, N. TAI, W. HUANG, J. LIU, and Y. WANG, "A review on protection of DC microgrids," J. Mod. Power Syst. Clean Energy, 2018.

[30] F. Aviation and Administration, "Advisory Circular," Area, no. January, pp. 1-4, 2005. 